\title{
Study on the Institutionalization of Cadres to Improve the Ability of Political Parties
}

\author{
Fengming Zhu' \\ ${ }^{1}$ School of Marxism, Qilu University, No. 2 Wenbo Road, Zhangqiu District, Jinan City, Shandong Province, \\ China
}

Keywords: Cadres can go down; Institutionalization; Political party capacity

\begin{abstract}
As far as China is concerned, the construction of cadre team has important practical significance for the improvement of party capacity building. At present, the construction of the cadre selection mechanism has been relatively sound and has achieved the goal of cadre, but how to improve the party's ability through the institutionalization of cadre can still be explored, and this is also the problem to be explored.

The capacity building of political parties maintains the survival of political parties and the development of political parties, and the promotion of political party's own management and political level is the main aspect of political party capacity building. Starting from this dimension, the capacity building of political parties should be "people-oriented", focusing on the development of political party capabilities from the perspective of people, and the relationship between core party members and political parties becomes the meaning of party capacity building.
\end{abstract}

\section{Institutionalization of Cadres is the Inevitable Choice for the Improvement of the Ability of Political Parties}

The generation of the party's ability includes the self-management of the party, the leadership of the party, and the construction of the governing function. In the later modern country, the capacity building of political parties should be matched with the political development. It should be carried out around the ability construction of the state, the rule of law and the responsible government. It is an inevitable choice to shape the ability of political parties to promote the ability of political parties.

\subsection{Institutionalization of cadres is the main indicator of the ability of political parties to govern}

Political parties have emerged and grown with the development of modern democratic politics, and democratic politics has also become the main tone of modern party politics. In modern times, political parties in the political process have evolved from interest groups of a sectarian nature in the past to trustees with interests coordinators and agents of state power. Therefore, the key to the existence and development of a political party is whether it can guarantee the consultation of interests between political parties and voters through the cadre appointment mechanism and guarantee the ability of political parties to control social development.

\subsection{Institutionalization of cadres is an inevitable choice to enhance the ability and legitimacy of political parties}

Institutionalized construction of cadres 'ability is an inevitable choice to enhance the ruling ability and legitimacy of Marxist political parties. The ruling status of the Communist Party of China is the choice of history and the people. However, this choice needs a mechanism to be expressed. By establishing the mechanism under which cadres can go down, they can shape an authorization mechanism between "citizens, political parties, and officials", timely eliminate unqualified officials, strengthen citizens 'recognition of political parties, and then consolidate the ruling basis of the regime. 


\subsection{Institutionalization of cadres is a guarantee for strengthening the capacity building of political parties}

Cadres can lower the operating costs of political parties to enhance the ability of political parties to build a guarantee. The existence of any organization requires a certain cost. Luonade·kesi, a representative of new institutionalism politics, believes that the basic significance of the existence of the system lies in reducing transaction costs. As a kind of organization composed of people, political parties incur costs due to the existence of certain "transaction costs" in their own management and administration.

\section{Feasibility Analysis of Institutionalizing the Ability of Political Parties with Cadres}

The promotion of the overall quality of the Party with the help of cadres has a sound academic basis for the capacity-building of political parties, and the ability of cadres not only relates to the growth of individual cadres, but also to the healthy development of the Party's cause. Cadres can not be arbitrary and subjective. To promote the ability of political parties through cadres, it is necessary to consolidate the party's ruling legitimacy and achieve the institutionalized development of cadres.

\subsection{Shaping the political party culture with the characteristics of the times promotes the institutionalization of cadres and promotes the improvement of political party capabilities.}

Institutionalized cadres can establish the mechanism needs to make a difference in the concept and consciousness. Therefore, one of the important prerequisites for the construction of cadres 'ability to solve the problem is to establish a modern party culture that is compatible with the political development of political parties. First of all, in the process of constructing party culture, we should construct the core party value that is consistent with the value orientation of democratic political development. When this political value is widely accepted, the time is ripe for constructing the cadre elimination mechanism through the internal Democratic mechanism. Secondly, in the regime characterized by "the party and the country as one", by building a participatory political party culture, citizens strengthen their recognition of political parties and use it to absorb better talents, and realize the ability of political parties to gather talents.At the same time, it provides alternative talent resources for the blank positions left by political party cadres after elimination, and thus enhances the overall ability of party members and realizes the development of political party capabilities. The construction of this kind of political culture should be characterized by participation, and the main goal is to construct a smooth passage between the "civil rights, party rights, and political power". Thirdly, to enhance the ability of political parties through the institutionalization of political parties should enhance the inclusiveness of party culture. Inclusion is one of the core features of contemporary party culture. Cadres can relate to the cadres 'own interests. An inclusive political party culture helps to ease the resistance of the eliminated cadres. It does not push these cadres to the opposite side of the political parties and becomes a negative resource for the improvement of political party capabilities and the smooth operation of political parties.

\subsection{Promoting the institutionalization of cadres under the rule of law and enhancing the capacity of political parties.}

The basic characteristic of modern party politics is the rule of law politics, the party is a legal party, and the ability of the party is externalized in the rule of law of the party's behavior. To promote the party's capacity building through institutionalized cadres, on the one hand, it is necessary to improve the party's legal system. On the other hand, the institutionalization of cadres can also be one of the important contents to promote the party's rule of law construction.

2.2.1. The institutionalization of cadres 'ability through inner-party regulations should solve the problem of scientific and flexible legislation and avoid the problem of "falling for the bottom".

In some places, the number of cadres at the municipal level, at the county level, at the age of 45, 
and at the township level, at the age of 35, has decreased, and in some cases the number of cadres who are required to enter the township team is under 30. This practice has a very bad impact on the overall construction of cadres. The legislative standards under cadres should be based on ability to legislate.

\subsubsection{The cadres 'ability to set standards should be clearly defined in the form of inner-party regulations, that is, there are laws to be followed.}

In order to ensure the institutionalization of cadres, emphasis should be placed on strengthening inner-party regulations.On the one hand, improve the scientific supervision and evaluation mechanism. Formulate the scientific basis for cadres to be able to set up a detailed evaluation standard system for cadres at different levels. According to the comprehensive considerations of morality, ability, diligence, performance, and integrity, strive for specificity and science, and avoid arbitrariness and contingency; We need to make supervision routine, be unique in our eyes and pay close attention, and ensure that key targets and key links are inspected. We need to be good at identifying competent cadres who are both active and excellent. We must also resolutely eliminate incompetent cadres who "when a monk hits a clock one day" and "have a hard hand and a soft hand"; We will improve the regular assessment system and conduct regular inspections based on strict, pragmatic, objective, impartial, serious and comprehensive criteria, so that cadres are honest, justified, and convinced.On the other hand, we will improve the supporting mechanisms for the management of cadres and introduce more operational specific systems and implementation rules, such as the implementation of early warning and recall mechanisms, and mobilize the enthusiasm of party members and cadres in their work; Gradually resign and dismiss the system to ensure the optimization and competence of the ranks of party members and cadres; Promote the appointment system and enhance the vitality of party members; We will improve the term of office system, ensure the continuity and stability of the ranks of Party members and cadres, and put an end to the artificial evasion caused by the gaps in the system.

\subsubsection{We need to establish a system of resettlement.}

Cadres can not only involve the punishment of cadres who violate laws and regulations, but also involve the reduction and exemption of cadres who are less capable. The success of the resettlement of the latter will be related to the operating costs of political parties and the improvement of the capacity of political parties. Therefore, we need to establish a management inspection mechanism for cadres who are able to do so, and to properly place cadres who are "under" in their posts. It is also necessary to establish compensation mechanisms for these party members through inner-Party laws and regulations, such as constructing a non-permanent "advisory group" and establishing it in the form of inner-party laws and regulations, which can compensate them to a certain extent and give them psychological care. It can also increase their enthusiasm for continuing to participate in the work of the Party and reduce the resistance to reform caused by it.

\subsection{Promote the institutionalization of cadres and the promotion of party capacity by building a democratic system within the party.}

The institutionalization of cadres can achieve the consensus within the party. Therefore, in the institutionalization of cadres, the system standards under cadres should be determined in a Democratic manner within the party, the scientific and Democratic construction of inner-party legislation should be achieved, and the resistance of cadres under the party should be reduced. Second, with the help of the existing Democratic tools within the party, we can reduce the institutional resistance of cadres, reduce the cost of reforms, and achieve the improvement of the ability of political parties.

\subsubsection{Improve the party's congress system and ensure the basic role of party members in cadres.}

The Party Congress is an important carrier of the party's internal elections. As the party's highest authority and the supervisory party's party congress, it is related to the rise and fall of the party's 
internal democracy. The scientific party congress system is the best system for the development of inner-party democracy. Design, there are many places for improvement, and the permanent system of the Party Congress is precisely a breakthrough in the development of intra-party democracy. It is necessary to repeatedly exchange the relationship between the party congress, the National Committee and the Party Congress. We must continue to explore the permanent system of the party congress and the tenure system reform of the party representatives in places where conditions permit, increase the supervision role of ordinary party members on leading cadres, achieve the normalization of cadre supervision, and promptly find incompetent cadres. Through the removal of existing procedures, the ability of the entire team of leading cadres is enhanced, and a certain foundation is laid for the democratic election of party members and leading cadres.

\subsubsection{Improve democratic centralism and consolidate the organizational foundation under which cadres can.}

Xi Jinping stressed that earnestly implement democratic centralism, improve the open system of administrative behavior, and ensure that leading cadres do not be good at power and do not seek personal gain. Perfect and powerful democratic centralism is the most reliable basis for our party to regulate the political life within the party, regulate the relations within the party, safeguard the interests of party members, and protect the party's ability to govern. It is the best, strongest, strictest and most secure to protect power against corruption. Prison, the highest institutional cage. In the current personnel dismissal, only the "head" is from the top leaders, that is, the golden rule, the squad leader, the acquaintances, the acquaintances, and other people, and the party organizations at all levels must follow the principle of democratic centralism. Activities, relying on a sound internal party supervision system, implementing strong and effective supervision, constructing a restrictive mechanism for exercising power according to law, and formulating objective criteria for judging the implementation of democratic centralism to strengthen the awe of each party member's democratic centralism. Du's absolute democratic centralism is not correct, implementation is weak, and implementation is not strict, and the realization of the party organization system that cadres can rely on to survive from a strong centralized system to a democratic system.

\subsubsection{Improve the discipline inspection system and enhance the supervision effect of the Commission for Discipline Inspection in the cadre.}

Improve the current disciplinary inspection system of the party's internal disciplinary committee, ensure the independence and compulsory of its supervision; establish a scientific, systematic and effective power restriction mechanism, and restrict the public power and the supervision of party members and leading cadres as the focus of supervision; The above-mentioned internal party supervision system will unblock the channels of supervision and realize the effective supervision of party members to the cadres and subordinates to the superiors. Increase the authorization of the Party Congress to the Disciplinary Committee, strengthen the responsible mechanism of the Disciplinary Committee on the Party Congress on the basis of the realization of the permanent system of the Party Congress and the term of the party representative. The Commission for Discipline Inspection shall promptly respond to the Plenary Meeting of the Party Committee at the same level and the Party Congress. Lead and put forward corresponding treatment suggestions so that the Disciplinary Committee can play a democratic supervision and handle the functions of unqualified party members.

\section{Conclusion}

In general, the institutionalization of cadre can be an inevitable choice to enhance the party's ability to manage and govern, and to improve the relationship between the parties and the social consensus. By realizing the institutionalization of cadres, it is possible to reduce the operating costs of political parties and enhance the party's management ability. Through the construction of the elimination mechanism for unqualified party members and leading cadres, the party's cohesiveness in the process of socialist construction and the improvement of the party's image will be enhanced. 
Enhance the party's ability to govern and consolidate the party's ruling foundation.

\section{References}

[1] Selected Works of Marx and Engels (Vol. 4), Beijing: People's Publishing House, 1995, p. 200.

[2] Selected Works of Deng Xiaoping (Vol. 1), Beijing: People's Publishing House, 1994, p. 329.

[3] David Koze. Ritual, Political, and Power, translated by Wang Haizhou, Nanjing: Jiangsu People's Publishing House, 2015, p. 31.

[4] Miao Yongquan, Fang Lei. "The Creative Transformation of Traditional Institutional Resources by the Inner Party Patrol System”, Theoretical Discussion, No. 3, 2016.

[5] Wang Yuxing. “The Theory of Party Competence in the Perspective of Political Party Political Politics", Learning and Exploration, No. 11 of 2012.

[6] The Information Office of the State Council of China, the Central Central Literature Research Office and the Chinese Foreign Languages Bureau. Xi Jinping's Talk on Governing the Country, Beijing: Foreign Languages Press, 2014 edition, p. 388. 